\title{
Comparing the Efficacy of Platelet-Rich Fibrin (PRF) With the Buccal Advancement Flap for the Closure of Acute Oroantral Communication
}

\author{
Dr. M. A. Awal ${ }^{1}$, Dr. Mahmuda Akhter ${ }^{* 2}$ \\ ${ }^{1}$ Oral and Maxillofacial Surgery Department, Bangabandhu Sheikh Mujib Medical University, Dhaka, Bangladesh \\ ${ }^{2}$ Oral and Maxillofacial Surgery Department, Bangabandhu Sheikh Mujib Medical University, Dhaka, Bangladesh \\ *Correspondence: Mahmuda Akhter; mahmudanaz@gmail.com
}

Received: 20 November 2020;

Accepted: 27 November 2020;

Published: 30 November 2020

\begin{abstract}
Oroantral communication (OAC) is a pathological communication between the oral cavity and the maxillary sinus. Numerous methods are described to manage an acute $\mathrm{OAC}$ with some adverse effect and limitations. Our comparative cross-sectional study tried to evaluate the efficacy of Platelet-rich fibrin (PRF) by comparing with the Buccal advancement flap for the closure of acute OAC on 38 patients ( $\mathrm{n}=38$ ), were divided into two groups. One group treated by traditional Buccal advancement flap and compared with the group treated with PRF clot and membranes. Statistically significant better healing with less complication was observed $(\mathrm{P}<0.05)$ in group treated with PRF clot and membranes considering as an effective way to manage acute oroantral communications.
\end{abstract}

Keywords: oroantral communication, platelet rich fibrin, baccal advancement flap.

\section{Introduction}

The pathological communication between maxillary sinus and oral cavity is known as the oro-antral communication (OAC). Maxillary molars and premolars have their roots projected within the maxillary antrum ${ }^{[1]}$. Extraction of maxillary molars and premolars may lead to oro-antral defect. Especially, the extraction of the first molars, are considered the most common causes of OAC ${ }^{[2]}$. If an OAC left untreated for more than 3 days, various complications like oroantral fistula and maxillary sinusitis may develop within 2 weeks ${ }^{[3]}$. Oroantral fistula may causes altered nasal resonance \& nasal regurgitation of fluid. An OAC with less than $3 \mathrm{~mm}$ usually closed spontaneously. Occasionally, OAC require repairment with local flaps or distal flaps. The most commonly used techniques are buccal advancement flap, palatal rotation-advancement flap and plastic techniques with the buccal fat-pad. Any surgical procedures have chances of failures, due to inadequate preoperative irrigation, existing sinus infection, excessive tension on the flap impairing blood supply for healing, lack of following post-operative instructions ${ }^{[1]}$. Most commonly, buccal advancement flap is commonly employed to correct the complication. In Buccal advancement flap procedure, a broad-based trapezoid mucoperiosteal flap is created and sutured over the defect which may causes reduction of the buccal sulcus depth and reduces postoperative pain and swelling ${ }^{[4]}$, which is imperative for the surgical correction.
Apart from the conventional procedures of treating OAC, Platelet rich fibrin (PRF) clot and membrane can also be used to repair OAC. Platelet rich fibrin (PRF) is a second-generation platelet concentrate containing large amount of platelets and growth factors embedded in fibrin matrix ${ }^{[5]}$. These platelets and growth factors decrease the inflammatory reactions and increased the healing capabilities of the tissues ${ }^{[6]}$. It's strong fibrin matrix with favorable mechanical properties ${ }^{[7]}$, like flexibility and elasticity, make PRF a biologically suitable graft for OAC ${ }^{[8]}$. Since it is an autologous product, it does not cause allergic reactions and there is no risk of disease transfer and no risk of donor site morbidity ${ }^{[5]}$.

This study was conducted to compare the clinical outcomes of both buccal advancement flap and PRF technique and thus evaluate the efficacy of PRF for the closure of acute OAC. It is found that PRF would be an effective alternative technique to Buccal advancement flap for the closure of acute OAC.

\section{Materials and methods}

It is comparative cross-sectional type study which is carried out in the department of oral and maxillofacial surgery, Bangabandhu Sheikh Mujib Medical University (BSMMU), Dhaka, Bangladesh from September 2019 to August 2020. The study was carried on patients who had acute OAC resulting from maxillary molar tooth extraction. 
Type of sampling were consecutive sampling. Patients having acute $\mathrm{OAC}$ measuring diameter of $4 \mathrm{~mm}$ to $9 \mathrm{~mm}$. with the inability to blow out the cheeks after the tooth extraction. Age ranges were in between 30 to 60 years. We excluded patients with acute $\mathrm{OAC}$ of $\geq 10 \mathrm{~mm}$ in diameter, having chronic inflammatory condition (Oroantral fistula), sinus infection (maxillary sinusitis).

Also, patient with any systemic diseases (diabetes, nephropathy, coagulation disorders, autoimmune diseases, cancers) were excluded.

Surgical Procedure: Detailed history of all patients was taken and clinical examination was done. Patient's general condition is assessed and exclude any comorbidity. Valsalva test was performed and site, duration and the diameter of the OAC was measured to decide whether the size of perforation was $>3 \mathrm{~mm}$, modification of ball burnisher instrument which was $3 \mathrm{~mm}$ in diameter was used. All data were recorded in predesigned data entry sheet.

\section{Group 1: Buccal advancement flap}

All of the operations were performed under local anesthesia. The wound was carefully washed and disinfected. In this technique, a broad-based trapezoid mucoperiosteal flap was created from the margin of the tooth socket up to buccal sulcus. The flap was reflected, advanced and sutured over the defect.

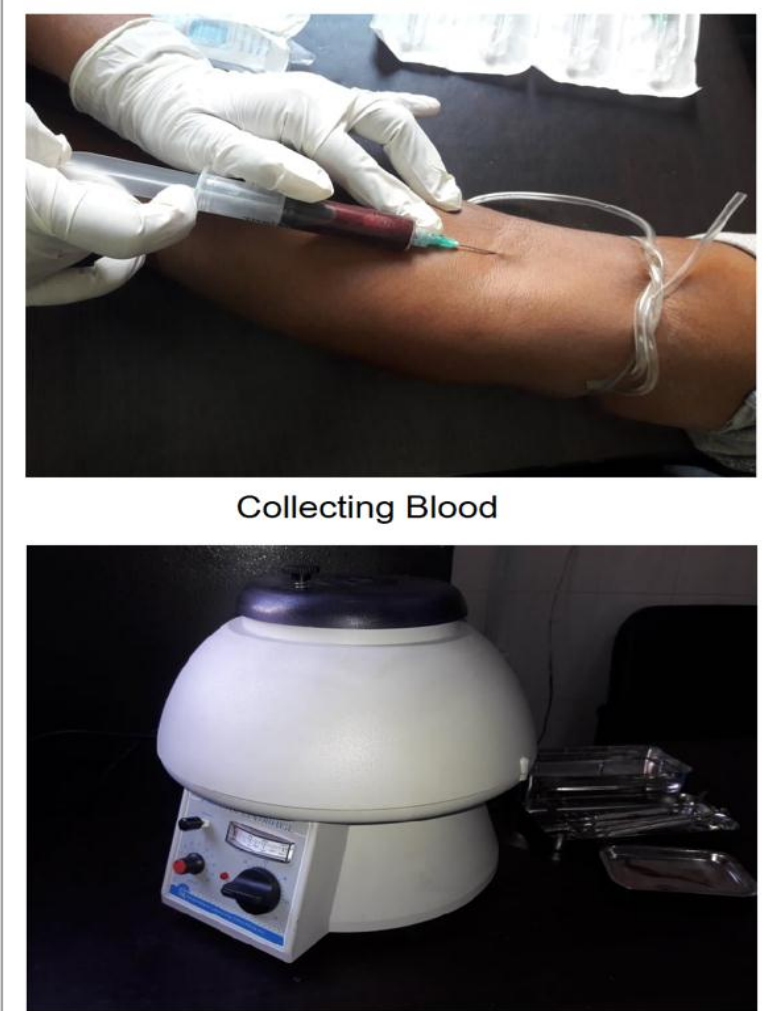

Centrifuge at $3000 \mathrm{rpm}$ for $10 \mathrm{~min}$

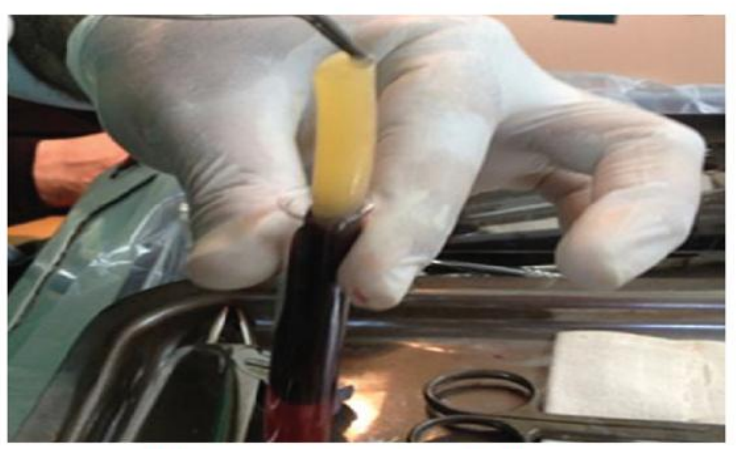

PRF separeting from RBC

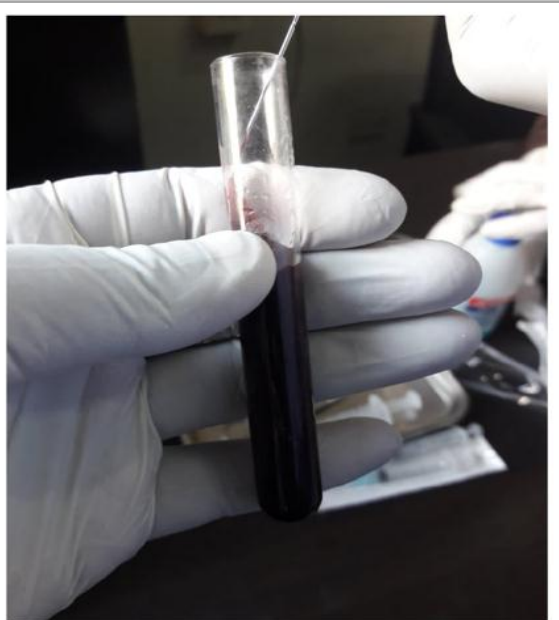

Test-tube without anticoagulent

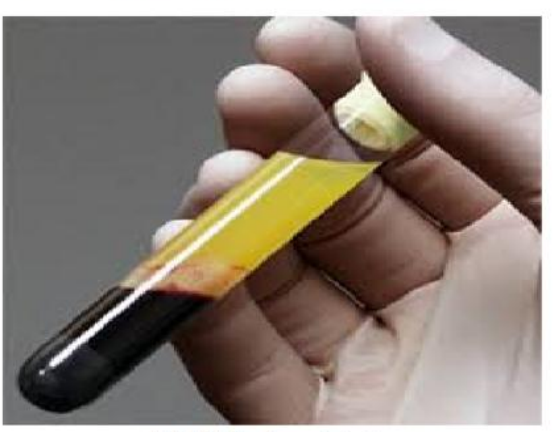

PRF in test-tube

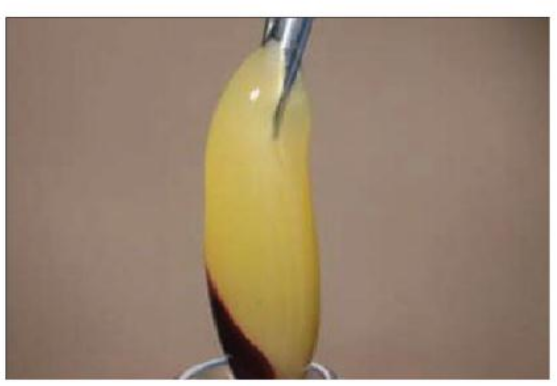

PRF

Figure1: Step by step preparation of platelet -rich fibrin (PRF). A table top centrifuge of model - DSC-200A-2 is used for preparation of PRF.

\section{Group 2: PRF clot and membrane}

All of the operations were performed under local anesthesia. The wound was carefully washed and disinfected. About $5 \mathrm{~mm}$ mucoperiosteal flap was elevated around the margin of the tooth socket. The bony socket or the alveolus was densely filled with a PRF clot and covered by another PRF membrane. PRF membrane covering the clot were sutured with 4-0 vicryl to the surrounding muco-periosteal flap.
Preparation of PRF clot and membrane: PRF clot and membrane was prepared during the surgical procedure. The PRF clot was prepared following Choukroun's PRF protocol5. After the venipuncture of median cubital vein, blood was taken without anticoagulant in two $10 \mathrm{ml}$ test-tubes which were immediately centrifuged at $3000 \mathrm{rpm}$ for 10 minutes. This clot was removed and placed on the PRF Box, to produce PRF clot and membrane in approximately $1 \mathrm{~min}$. 


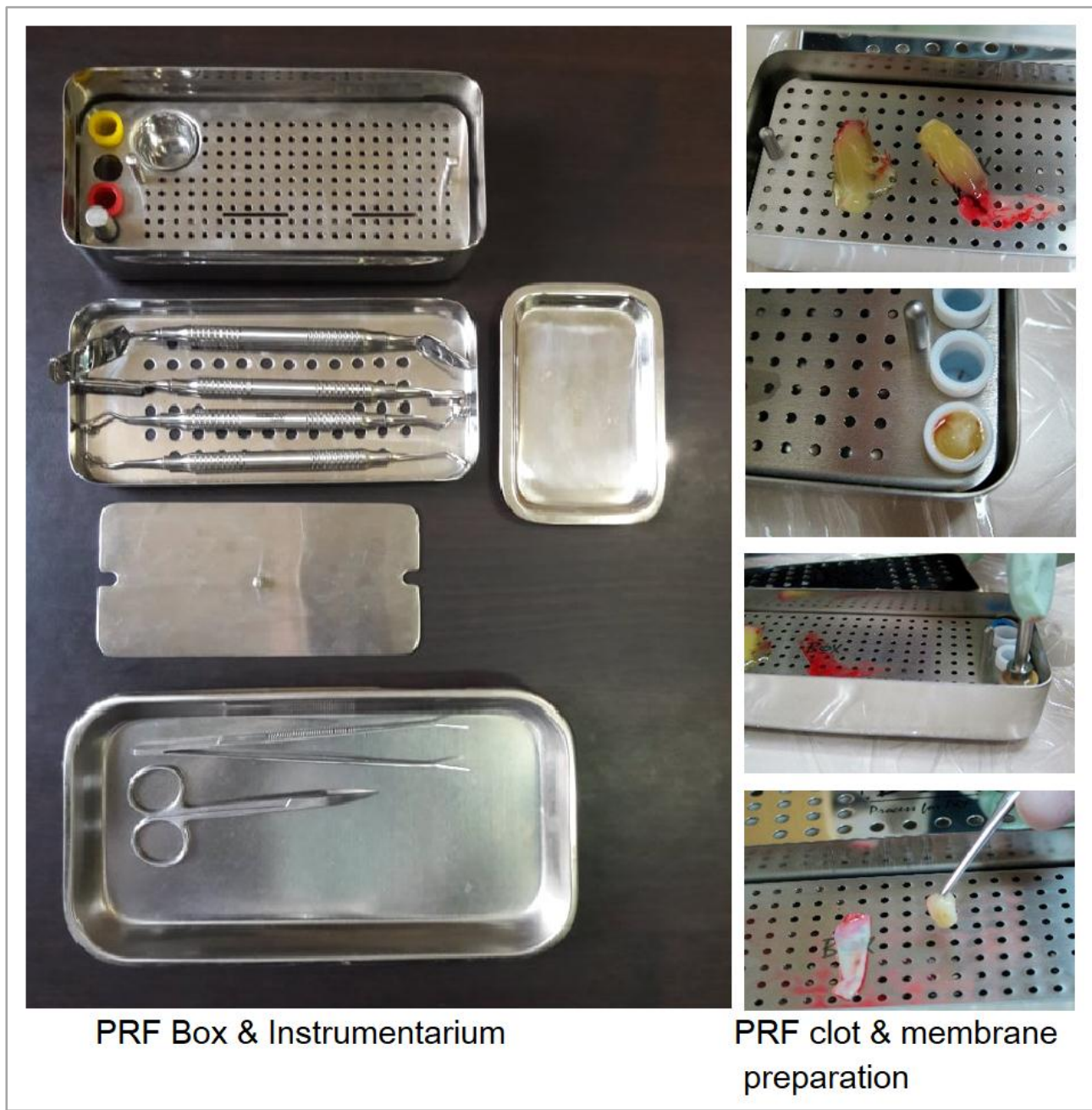

Figure 2: A set of PRF Box with Instruments. Step by step fabrication of platelet-rich fibrin (PRF) clot \& membrane.

The PRF clot was placed on the grid in the PRF Box and covered with the compressor lid. The ideal weight of the lid compressed the clots and flattened them to create an autologous fibrin membrane in approximately one minute. The PRF Box was devised to produce membranes of constant thickness that remain hydrated for several hours.

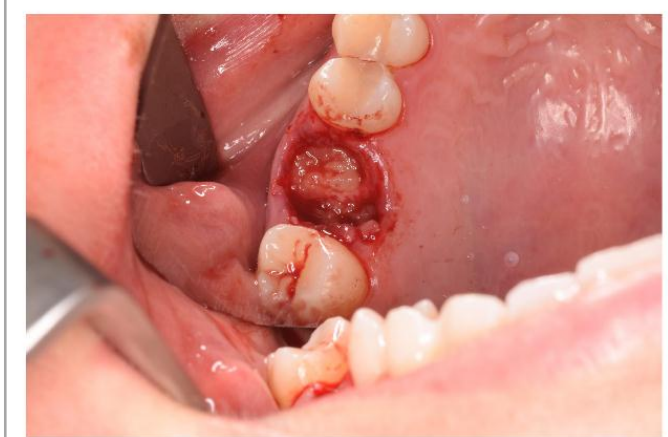

PRF Plugged in the Socket

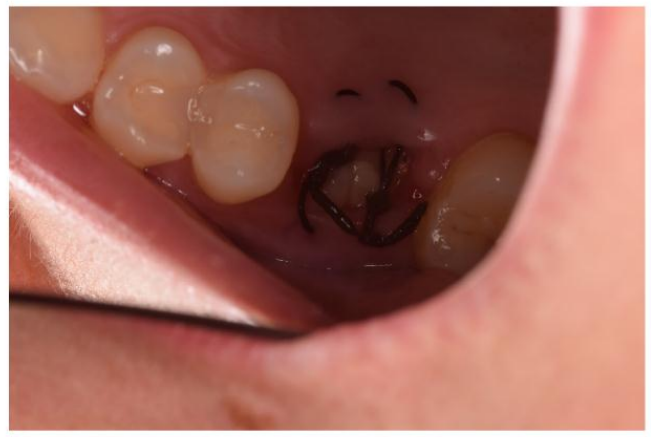

7th POD

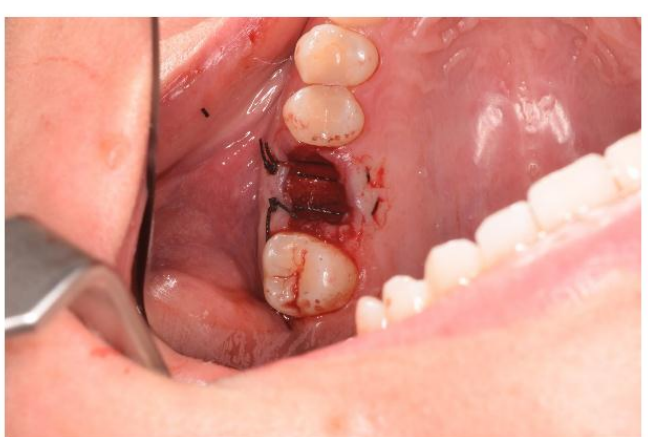

1st POD

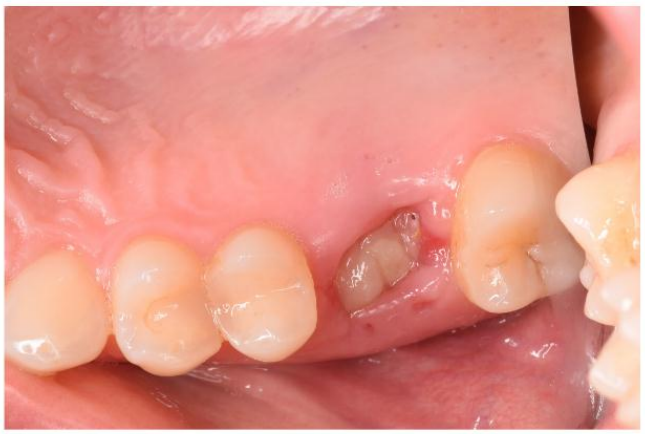

14th POD

Figure 3: Pre and Post-surgical condition of an Oroantral communication treated with platelet-rich fibrin clots and membrane. 
Postoperative care: Instruction was given about a soft diet, postoperative oral hygiene to the patient. The patients were instructed to avoid strenuous physical activities (nose blowing, sneezing, using straws, outdoor strenuous activities). The sutures were removed 7 days after surgery.

All patients were previously informed and agreed to attend postoperative follow up visit on the 1st, 7 th and 14th day after the surgery to assess:

1. The level of post-operative pain (Visual Analog Scale VAS)

2. Inflammatory condition of the surgical wound (Clinical Healing Score - CHS)

3. Healing progress of the surgical wound (Clinical Healing Score - CHS

The level of post-operative pain (VAS)

The level of postoperative pain was measured with the aid of the Visual Analog Scale (VAS) on the 1st, 7th and 14th day after the intervention. Absence of pain was considered to be 0 , while the strongest pain indicates 10 .

\section{Inflammatory condition of the surgical wound (CHS)}

Clinical measurement of inflammatory response and mode of wound healing were done using CHS. Assessment of redness and edema indicate inflammatory response and presence of healthy granulation tissue and presence of epithelization indicate mode of healing. A healing score of 0 indicates no inflammation and better healing, when score 4 indicates absence of healing with inflammation. The results of the CHS were measured on the 1st, 7th and 14th day after the intervention.
Data analysis: Statistical analyses were performed using Independent Samples $t-$ Test (t), to compare the means of 2 independent groups. In addition, the Chi-Square test (x2) was used to compare categorical variables. A p-value of $<0.05$ was considered to be statistically significant. The data was presented in the form of tables and figures as necessary. SPSS 22 was used to perform statistical analysis.

Ethical consideration: Ethical clearance for the study was taken from the Institutional Review Board (IRB) of BSMMU prior to the commencement of this study. The aims and objectives of the study along with its procedure, risks, stages and benefits of this study were explained to the study subjects in an easily understandable local language. A written informed consent was taken from all the study subjects. All the study subjects were assured about their confidentiality and freedom to withdraw themselves from the study at any time.

\section{Results}

\section{Size of OAC}

Table 1 shows, from the Group- 1 the maximum patients, 10 $(52.63 \%)$ had OAC of $5 \mathrm{~mm}$ size and 5 patients $(26.32 \%)$ had 4 $\mathrm{mm}, 3$ patients $(15.79 \%)$ had $6 \mathrm{~mm}$ and only $1(5.26 \%)$ had $7 \mathrm{~mm}$ size OAC. The mean size of the OAC in Group 1 was $5 \mathrm{~mm}$ where standard deviation is \pm 0.82 . The same table also shows, from the Group-2 the maximum patients, $8(42.11 \%)$ had OAC of $5 \mathrm{~mm}$ size and 8 patients (42.11\%) had $4 \mathrm{~mm}, 2$ patients $(10.53 \%)$ had $6 \mathrm{~mm}$ and only $1(5.26 \%)$ had $7 \mathrm{~mm}$ size OAC. The mean size of the OAC in Group 2 was 4.78 with standard deviation \pm 0.85 .

Table 1: Distribution of patients by the size of OAC

\begin{tabular}{|l|l|l|l|l|}
\hline \multirow{2}{*}{ Size $(\mathbf{m m})$} & Group 1 & Group 2 & \% \\
\cline { 2 - 5 } & $\mathbf{n}$ & $\mathbf{\%}$ & $\mathbf{n}$ & 42.11 \\
\hline 4 & 5 & 26.32 & 8 & 42.11 \\
\hline 5 & 10 & 52.63 & 8 & 10.53 \\
\hline 6 & 3 & 15.79 & 2 & 5.26 \\
\hline 7 & 1 & 5.26 & 1 & 100 \\
\hline Total & 19 & 100 & 19 & $4.78 \pm 0.85(4-7)$ \\
\hline Mean \pm SD (Min-Max) & $5 \pm 0.82(4-7)$ & & \\
\hline
\end{tabular}

In table 2 mean VAS of Group 1, who were managed with buccal advancement flap, on 24 hours was 7.05 , on 7 th post-operative day 5.05 and on 14th post-operative day 1.05. Standard deviations were $0.62,0.70$ and 1.02 accordingly. Mean VAS of group 2, where PRF was used to manage acute OAC on 24 hours was 5.26 , on 7 th postoperative day 3.74 and on 14 th post-operative day 0.21 . Standard deviations were $0.56,0.73$ and 0.63 accordingly.
Also, the comparison of VAS between Group 1 and Group 2 . Results indicated that, VAS (post-operative pain) was significantly less in Group 2, than Group 1 on 24 hour, 7th and 14th postoperative day. $\mathrm{P}$ value is statistically significant in all observations.

Table 2: Comparison of VAS Scores on 1st, 7th and 14th post-operative days:

\begin{tabular}{|l|l|l|l|l|l|l|}
\hline VAS & Group 1 (Buccal flap) & Group 2 (PRF) & Mean \pm SD & t value & $P^{*}$ \\
\hline Day & $\mathrm{n}$ & Mean \pm SD & $\mathrm{n}$ & 19 & $5.26 \pm 0.56$ & 9.311 \\
\hline $1^{\text {st }}$ Day & 19 & $7.05 \pm 0.62$ & 19 & $3.74 \pm 0.73$ & 5.637 & $<.000001$ \\
\hline $7^{\text {th }}$ Day & 19 & $5.05 \pm 0.70$ & 19 & $0.21 \pm 0.63$ & 3.048 & $<.00215$ \\
\hline $14^{\text {th }}$ Day & 19 & $1.05 \pm 1.02$ & & & \\
\hline
\end{tabular}

*The result is significant at $p<.05$.

In Table 3 shows the comparison of VAS Scores (Sum of 24 hour, 7th and 14th post-operative days) between Group 1 and Group 2. Results indicated that, mean VAS (post-operative pain) was significantly less in Group 2 than Group 1. P value is statistically significant $(<.00001)$ 
Table 3: Comparison of VAS Scores between Group 1 and Group 2.

\begin{tabular}{|l|l|l|l|l|l|}
\hline & \multicolumn{2}{|l|}{ VAS } & & \\
\cline { 1 - 5 } Group & $\mathrm{n}$ & Min - Max & Mean \pm SD & $t$ & $p^{*}$ \\
\cline { 1 - 5 } Group 1 (Buccal flap) & 19 & $10-16$ & $13.16 \pm 2.00$ & 6.787 & $<.00001$ \\
\cline { 1 - 3 } Group 2 (PRF) & 19 & $8-13$ & $9.21 \pm 1.55$ & \\
\hline
\end{tabular}

$*$ The result is significant at $p<.05$.

Assessment of inflammatory response and presence of healthy granulation tissue and presence of epithelization indicate mode of healing. Table 4 shows Clinical Healing Score (CHS) in both group $1 \& 2$. Sum of four criteria was measured on 1 st, 7 th and 14th postoperative day, where 0 indicates no inflammation and better healing, and score 4 indicates absence of healing with inflammation. Mean CHS of both group were compared. Results indicated that, CHS was significantly less in Group 2, than Group 1. $P$ value is also statistically significant $(p<.00235)$

Table 4: Comparison of Clinical Healing Scores

\begin{tabular}{|l|l|l|l|l|l|}
\hline & \multicolumn{2}{|l|}{ CHS } & & \\
\cline { 1 - 4 } Group & $\mathrm{n}$ & Min - Max & Mean \pm SD & $t$ & $p^{*}$ \\
\cline { 1 - 4 } Group 1(Buccal flap) & 19 & $5-8$ & $6.26 \pm 0.99$ & 3.014 & $<.00235$ \\
\cline { 1 - 3 } Group 2 (PRF) & 19 & $4-8$ & $5.32 \pm 0.95$ & & \\
\hline
\end{tabular}

$*$ The result is significant at $p<.05$.

\section{Discussion}

There are few articles where very little data for the usage of PRF as an independent grafting material in the treatment of acute OAC. Thus, the result of this present study could not be compared statistically with same types of previous studies.

In 2011, Agarwal et al. indicated an alternative method for the management of OAF with use of PRF clots. They used cylinder-shaped fibrin plug to obturate the fistula ${ }^{[10]}$. Gulsen et al. reported that 20 patients with acute OAC with perforations more than $5 \mathrm{~mm}$ in diameter treated with the PRF clots. His study showed that the PRF had been transformed into healthy granulation tissue after 7 days and three weeks postoperatively complete healing and epithelization was apparent. Chenchev et el. used the Clinical Healing Score (CHS) in their study to determine the clinical results. They conclude their results showing a minimal postoperative discomfort for the patients and a quick epithelization of the alveolus (OAC) over a period of 7 days ${ }^{[11]}$. The most relevant immediate postoperative complications were pain $(31.25 \%)$, edema $(25 \%)$ and trismus $(12.5 \%)^{[12]}$. Bilginaylar reported that 21 acute $\mathrm{OAC}$ were treated with the application of 2 PRF clots where the perforation was more than $3 \mathrm{~mm}$ in diameter. Baseline variables of his study were post-operative pain, analgesic doses taken, and swelling. He showed, statistically significant reduction of pain $(\mathrm{P}<0.05)$ in $\mathrm{PRF}$ group and swelling was also significantly less $(\mathrm{P}<0.05)$ in PRF group ${ }^{[9]}$.

Although there are some differences between these approaches, such as amount of PRF and form of application (clots or membrane or both together). All approaches revealed that PRF could be successfully used for the treatment of OAC.

In our study it is found indicated that, VAS (post-operative pain) was significantly less in Group 2, than Group 1 on 24 hour, $7^{\text {th }}$ and $14^{\text {th }}$ post-operative day. $\mathrm{P}$ value were statistically significant in all observations. Results summarized that, mean VAS (postoperative pain) was significantly less in Group $2(9.21 \pm 1.55)$ than Group 1 (13.16 \pm 2.00$)$. P value is also statistically significant (< $.00001)$.

Also, CHS is used to assess inflammatory response and mode of healing through the presence and absence of redness, edema, healthy granulation tissue and epithelization on the surgical site. Results indicated that, CHS was significantly less in Group 2 (5.32 \pm 0.95$)$, than Group $1(6.26 \pm 0.99)$. $P$ value was also statistically significant $(<.00235)$.
Choukroun reported the use of PRF first of the kind, especially in oral and maxillofacial surgery, and it was considered as a new generation of platelet concentrate ${ }^{[13]}$. The preparation of PRF clot and membrane is very simple and easy and can be produced within very short period of time. The centrifuge is inexpensive and requires minimal training for the clinician and their support staff. Moreover, the surgical procedure was less invasive and can be completed under local anesthesia.

The results of present study summarized that; the subjective and clinical outcomes of PRF were statistically significant when compared to Buccal advancement flap.

\section{Conclusion}

From this study, it can be concluded that, PRF procedure showed decreased pain, less inflammatory response and better healing compared to buccal advancement flap surgery. Hence, efficacy of PRF is sufficient for the treatment of acute OAC and PRF could be an alternative treatment option for closure of acute OAC.

\section{Limitations}

- Small sample size.

- Diameter of OAC was less than $10 \mathrm{~mm}$.

- It was a single centered study.

- Non random sampling method.

\section{Recommendations}

In the light of findings of the present study, PRF clot and membrane could be used as an effective treatment option for acute OAC. However, multi-centric, population based comparative studies with follow up are required for further development.

\section{Conflict Of Interest}

Authors declared no conflict of interest

\section{References}

[1] Hassan O, Shoukry T, Raouf AA, Wahba H. (2012), Combined palatal and buccal flaps in oroantral fistula 
repair. Egypt J Ear, Nose, Throat Allied Sci. Vol:13, Pages: 77-81

[2] Hirata Y, Kino K, Nagaoka S, Miyamoto R, Yoshimasu H, Amagasa T. (2001) A clinical investigation of oromaxillary sinus-perforation due to tooth extraction. Kokubyo Gakkai Zasshi. Volume: 68(3), Pages: 249-253.

[3] Scattarella A, Ballini A, Grassi FR, Carbonara A, Ciccolella F, Dituri A, Nardi GM, Cantore S, Pettini F (2017) Treatment of oroantral fistula with autologous bone graft and application of a non-reabsorbable membrane, Int J Med Sci. Vol: 7(5) Pages :267-71.

[4] Akram Belmehdi and Karima El Harti, (2019). Management of oroantral communication using buccal advanced flap, The Pan African Medical Journal, Volume: 34, Pages: 69-72.

[5] Dohan DM, Choukroun J, Diss A, Dohan SL, Dohan AJ, Mouhyi J, Gogly B. (2006). Platelet-rich fibrin (PRF): a second-generation platelet concentrate. Part I: technological concepts and evolution. Oral Surgery, Oral Medicine, Oral Pathology, Oral Radiology, and Endodontics, Volume:101, Pages: e37- e44

[6] Kanno T, Takahashi T, Tsujisawa T, Ariyoshi W, Nishihara T. (2005) Platelet-rich plasma enhances human osteoblast-like cell proliferation and differentiation. $J$ Oral Maxillofac Surg Vol: 63, Pages: 362-9.

[7] Wu, C. L., Lee, S. S., Tsai, C. H., Lu, K. H., Zhao, J. H., \& Chang, Y. C. (2012). Platelet-rich fibrin increases cell attachment, proliferation and collagen-related protein expression of human osteoblasts, Australian Dental Journal, Volume: 57(2), Pages: 207-212.

[8] Andreas Anwandter, Stephanie Bohmann, MauricioNally, Ana B.Castro, MarcQuirynen, NelsonPintocd, (2016), Dimensional changes of the post extraction alveolar ridge, preserved with Leukocyte- and Platelet Rich Fibrin: A clinical pilot study, Journal of Dentistry, Volume 52, Pages 23-29

[9] Bilginaylar K. (2019), The Use of Platelet-Rich Fibrin for Immediate Closure of Acute Oroantral Communications: An Alternative Approach, Journal of Oral and Maxillofacial Surgery, Volume 76, Pages 278286.

[10] Agarwal B, Pandey S, Roychoudhury A. (2016), New technique for closure of an oroantral fistula using platelet-rich fibrin. Br J Oral Maxillofac Surg, Volume 54, Page: e31-e32.

[11] Chenchev I, Neichev D, Atanasov D, Dobreva D, (2016), Oroantral Communication Repair Using Platelet-Rich Fibrin, IOSR Journal of Dental and Medical Sciences, Volume 15, Page: 100-104.

[12] Bitar W. Assad M. Alhajj MN. (2017), Closure of oroantral communication using platelet rich fibrin: a report of two cases, Ann Maxillofac Surg, Volume 7, Pge: 117-119.

[13] Choukroun J, Diss A, Simonpieri A, Girald M et al., (2006), Platelet-rich fibrin (PRF): a second-generation platelet concentrate, Oral Surg Oral Med Oral Pathol Oral Radiol Endod, Volume 101, Page: 299-303. 